\title{
Predictive Factors for Lymph Node Metastasis and the Effect on Survival in Early Gastric Cancer Patients with Radical Gastric Resection
}

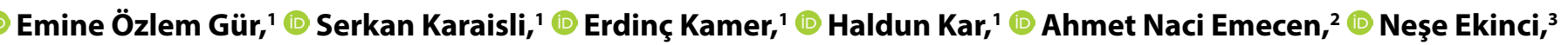 \\ Osman Nuri Dilek,' 1 (1) Mehmet Haciyanlı'
}

'Department of General Surgery, Katip Celebi University Faculty of Medicine, Ataturk Training and Research Hospital, Izmir, Turkey ${ }^{2}$ Department of Public Health, Dokuz Eylul University Faculty of Medicine, Izmir, Turkey

${ }^{3}$ Department of Pathology, Katip Celebi University Faculty of Medicine, Ataturk Training and Research Hospital, Izmir, Turkey

\begin{abstract}
Objectives: Selected patients with early gastric cancer (GC) are treated endoscopically. Lymph node metastasis (LNM) in the T1 stage may also be detected during surgical resection for early GC. The aim of this study was to determine factors associated with LNM and the effect on survival.

Methods: A total of 63 patients with tumor invasion stage T1a or T1b who were operated on for early GC between 2010 and 2018 were included in the study. Parameters were investigated retrospectively to identify predictive factors for LNM and overall survival. Significance was defined with a 2-sided p-value of $<0.05$.

Results: Among the 63 patients, 21 (33.3\%) had LNM. Lymphovascular invasion (LVI) ( $p=0.02)$ and a high-grade tumor ( $p=0.02)$ were significantly associated with LNM. The overall survival rate was $73.0 \%$. The number of patients with LNM was greater among the deceased patients compared with the censored group $(p=0.03)$. The median follow-up time of the entire group was 28 months (range: 12-55 months) while it was 23 months (range: 7-39 months) in the deceased group and 33.5 months (15.5-60 months) in the censored group $(p=0.06)$. The mean survival was 62.36 months in patients with LNM and 71.99 months in those without LNM $(p=0.09)$. The cut-off value determined for the neutrophil-to-lymphocyte ratio (NLR) was 2.33 and it was an effective value in survival analysis $(p<0.05)$.

Conclusion: Surgical treatment should be considered for early GC patients with high-grade tumors and cases demonstrating LVI. The overall survival was shorter in patients with a high NLR value and LNM.

Keywords: Early gastric cancer; gastric cancer; lymph node metastasis.

Please cite this article as "Gür EÖ, Karaisli S, Kamer E, Kar H, Emecen AN, Ekinci N, et al. Predictive Factors for Lymph Node Metastasis and the Effect on Survival in Early Gastric Cancer Patients with Radical Gastric Resection. Med Bull Sisli Etfal Hosp 2019;53(4):371-378".
\end{abstract}

G astric cancer (GC) is the second most common reason Jor cancer-related death after lung cancer. Endoscopic resection for selected cases in early GC has become a frequently used method in recent years as an alternative treat- ment to surgery. ${ }^{[1]}$ Endoscopic submucosal dissection (ESD) has developed in recent years and has begun to be applied in cases of differentiated tumors as well as tumors $<2 \mathrm{~cm}$ in diameter. ${ }^{[2]}$ Some studies have indicated that there is no

Address for correspondence: Emine Özlem Gür, MD. Ataturk Egitim ve Arastirma Hastanesi, Katip Celebi Universitesi Tip Fakultesi, Genel Cerrahi Anabilim Dali, Izmir, Turkey

Phone: +90 5323666778 E-mail: eozlemgur@yahoo.com

Submitted Date: August 20, 2019 Accepted Date: August 27, 2019 Available Online Date: November 19, 2019

${ }^{\circ}$ Copyright 2019 by The Medical Bulletin of Sisli Etfal Hospital - Available online at www.sislietfaltip.org

OPEN ACCESS This is an open access article under the CC BY-NC license (http://creativecommons.org/licenses/by-nc/4.0/). 
risk of lymph node metastasis (LNM) in hypertrophic early GC. The main criteria for endoscopic resection in early GC have been the degree of differentiation, the size of the tumor, and the risk of LNM. ${ }^{[3]}$

The primary factors affecting prognosis in early GC are tumor differentiation and LNM. The presence or absence of LNM is related to tumor differentiation, but mixed-type pathological features in GC are possible. In the preoperative diagnosis period, oftentimes, the pathologist will not mention the degree of differentiation in cases of early GC. ${ }^{[4]}$ Mixed-type differentiation is detected in about $25 \%$ of these patients. ${ }^{[5,6]}$

Studies have shown that the rate of LNM varies between $0 \%$ and $12 \%$ in early GC with tumors that have T1a features, are well differentiated, are nonulcer forming, and $<2 \mathrm{~cm}$ in size. ${ }^{[7-9]}$ Since LNM is an important prognostic and therapeutic criterion, it is emphasized that patients who are to undergo ESD should have preoperative computed tomography $(\mathrm{CT})$ imaging and a detailed examination. ${ }^{[8-10]}$

The aim of this study was to identify predictive factors of LNM in early GC patients who underwent gastrectomy and the effect of LNM on the overall survival.

\section{Methods}

The study group included in this retrospective study comprised 382 patients who were operated on for palliative or curative purposes due to GC in a single clinic between 2010 and 2018. All of these patients underwent distal or total gastric resection. The tumor stage was assigned by matching the depth of invasion to the American Joint Committee on Cancer Staging Manual. ${ }^{[11]}$ Tis (tumor in situ) disease was defined as tumors confined to the epithelium, T1a disease was defined as tumors limited to the lamina propria or the mucosa, and $\mathrm{T} 1 \mathrm{~b}$ disease was defined as tumors that were restricted to the submucosal layer of the stomach wall. The tumor grade was divided into 4 categories: well differentiated (grade 1), moderately differentiated (grade 2), poorly differentiated (grade 3), and undifferentiated/anaplastic (grade 4).

Patients with T1a and T1 b tumors according to the T-stage of the TNM classification were included in the study. Patients who had neoadjuvant therapy or who had undergone gastric surgery for any reason were excluded. In total, 63 cases were included in this study.

Inclusion criteria

1. Preoperative pathologically determined gastric cancer diagnosis

2. Older than 18 years of age
3. Preoperative endoscopy was performed

4. No spreading according to preoperative CT scan

5. Postoperative pathological $\mathrm{T}$ stage is $\mathrm{T} 1 \mathrm{a}$ or $\mathrm{T} 1 \mathrm{~b}$

Exclusion criteria

1. Preoperative endoscopic treatment (ESD) was possible

2. Neoadjuvant chemotherapy was performed

3. Postoperative pathological $\mathrm{T}$ stage of $\mathrm{T} 2, \mathrm{~T} 3, \mathrm{~T} 4$

The dependent variables of the study were LNM and survival. The patients were divided into groups according to the postoperative pathology: Patients with LNM were classified as Group 1 and patients without LNM as Group 2. The independent variables were the number of dissected lymph nodes; age; sex; tumor grade; T stage of the tumor; lymphovascular invasion (LVI); perineural invasion; tumor diameter; c-erbB-2 status of the tumor; tumor location (antrum, corpus, cardia); levels of hemoglobin, albumin, neutrophils (number/dL), lymphocytes (number/dL), and monocytes (number/dL); neutrophil-to-lymphocyte ratio (NLR); lymphocyte-to-monocyte ratio (LMR); and the neutrophil-to-monocyte ratio (NMR).

The length of follow-up of the patients after the surgery was recorded and parameters that were related to overall survival were investigated.

Ethics committee approval for this study was received from the Ethics Committee of Katip Celebi University (date: 02.14.2018, decision number: 34 ) and the research was performed in accordance with the principles of the Declaration of Helsinki and its appendices. Written, informed consent was obtained from all of the patients who participated in this study.

\section{Statistical Analysis}

Descriptive statistics were presented as number and percentage for categorical variables and mean and standard deviation were used for continuous variables. Univariate comparisons were made using a chi-square test or Fisher's exact test for categorical variables and the Mann-Whitney $U$ test for continuous variables. The optimal cut-off of NLR for survival was determined to be 2.332 using the maximal point of the Youden index $(\mathrm{YI}(\mathrm{C})=\operatorname{maxc}($ sensitivity(c)+specificity(c)-1). ${ }^{[12]}$ NLR levels $>2.332$ were categorized as high. Kaplan-Meier survival curves were calculated and a log-rank test was used to compare the mean survival time of the groups.

Cox hazard regression models were developed to illustrate the independent effect of each variable on survival. Variables with a $p$ value of $<0.10$ (LNM, LVI, and high NLR) were included in multivariate Cox regression models. Model 1 
included age and gender as potential confounders with either LNM, LVI, or high NLR. Model 2 included all 3 variables with age and gender.

Statistical analyses were performed using $R$ version 3.4.3 ( $R$ Core Team (2017). R: A language and environment for statistical computing. R Foundation for Statistical Computing, Vienna, Austria. URL http://www.R-project.org/). The OptimalCutpoints package was used to estimate the optimal cut-off for NLR. Survival curves were generated with the Survminer package and survival data was analysed with the Survival package, using the Breslow method to address tied event times. Significance was defined with a 2 -sided $p$ value of $<0.05$.

\section{Results}

Of the 63 patients included in the study, 21 (33.3\%) had LNM. LNM-positivity was greater in patients with LVI $(61.5 \%$ vs $26.0 \%)(p=0.02)$ and in patients with a high-grade tumor $(46.9 \%$ vs $19.4 \%)(p=0.02)$. There was no statistically significant correlation between LNM status and gender, BMI, tumor location, tumor size, type of gastrectomy procedure performed, stage, perineural invasion, blood group, or Rh status ( $p>0.05$ for all), as seen in Table 1.

The mean levels of clinicopathological and laboratory parameters according to LNM status are presented in Table 2. The mean age was 57.7 years in the LNM-positive group and 62.52 years in the LNM-negative group $(p=0.09)$. The neutrophil, lymphocyte, and monocyte counts were not statistically different between LNM groups $(p=0.69, p=0.62$, and $p=0.28$, respectively). The inflammatory values of C-reactive protein, NLR, LMR, and NMR were not significantly different between LNM groups.

The c-erbB-2 receptor was evaluated in 20 of the patients (31.7\%). Of the 20 patients, 6 (30.0\%) were c-erbB-2 receptor-positive. LNM positivity was $16 \%$ in c-erbB-2 receptorpositive patients compared with $42.8 \%$ in c-erbB- 2 receptor-negative patients. There was no statistically significant difference in LNM-positivity between c-erbB-2 groups $(p=0.35)$.

\section{Effect of LNM on Overall Survival}

Seventeen patients (26.9\%) died during the follow-up period. The overall survival rate of the group was $73 \%$. The mean age of the deceased group was $62.94 \pm 10.93$ years and the mean was $60.17 \pm 9.73$ years in the censored group $(p=0.22)$. The median length of follow-up of the entire group was 28 months (range: 12-55 months), while it was 23 months (range: 7-39 months) in the deceased group and 33.5 months (range: 15.5-60 months) in the censored group $(p=0.06)$. The number of metastatic lymph nodes
Table 1. Demographic, clinicopathological, and laboratory parameters of the LNM and non-LNM groups

\begin{tabular}{|c|c|c|c|}
\hline & $\begin{array}{c}\text { LNM }(\mathbf{n}=\mathbf{2 1})^{*} \\
n(\%)\end{array}$ & $\begin{array}{c}\text { Non-LNM }(n=42) \\
n(\%)\end{array}$ & $\mathbf{p}$ \\
\hline Gender & & & 0.71 \\
\hline Male $(n=41)$ & $13(31.7)$ & $28(68.3)$ & \\
\hline Female $(n=22)$ & $8(36.4)$ & $14(63.6)$ & \\
\hline BMI & & & 0.55 \\
\hline Weak $(n=6)$ & $3(50.0)$ & $3(50.0)$ & \\
\hline Normal $(n=38)$ & $13(34.2)$ & $25(65.8)$ & \\
\hline Obese $(n=19)$ & $5(26.3)$ & $14(73.7)$ & \\
\hline Tumor location & & & 0.29 \\
\hline Antrum $(n=43)$ & $16(37.2)$ & $27(62.8)$ & \\
\hline Corpus $(n=13)$ & $2(15.4)$ & $11(84.6)$ & \\
\hline Cardia $(n=7)$ & $3(42.9)$ & $4(57.1)$ & \\
\hline Tumor size & & & 0.38 \\
\hline$\leq 1 \mathrm{~cm}(\mathrm{n}=21)$ & $5(23.8)$ & $16(76.2)$ & \\
\hline $1-3 \mathrm{~cm}(\mathrm{n}=23)$ & $10(43.5)$ & $13(56.5)$ & \\
\hline$\geq 3 \mathrm{~cm}(\mathrm{n}=19)$ & $6(31.6)$ & $13(68.4)$ & \\
\hline Gastrectomy & & & 0.84 \\
\hline Total $(n=16)$ & $5(31.2)$ & $11(68.8)$ & \\
\hline Distal $(n=47)$ & $16(34.0)$ & $31(66.0)$ & \\
\hline Stage & & & 0.37 \\
\hline $1 \mathrm{a}(\mathrm{n}=26)$ & $7(26.9)$ & $19(69.1)$ & \\
\hline $1 b(n=37)$ & $14(37.8)$ & $23(62.2)$ & \\
\hline Grade & & & 0.02 \\
\hline Low $(n=31)$ & $6(19.4)$ & $25(80.6)$ & \\
\hline High $(n=32)$ & $15(46.9)$ & $17(53.1)$ & \\
\hline Lymphovascular invasion & & & 0.02 \\
\hline Yes $(n=13)$ & $8(61.5)$ & $5(38.5)$ & \\
\hline No $(n=50)$ & $13(26.0)$ & $37(74.0)$ & \\
\hline Perineural invasion & & & 0.11 \\
\hline Yes $(n=2)$ & $2(100.0)$ & $0(0.0)$ & \\
\hline No $(n=61)$ & $19(31.1)$ & $42(68.9)$ & \\
\hline C-erb-B2 & & & 0.35 \\
\hline Positive $(n=6)$ & $1(16.7)$ & $5(83.3)$ & \\
\hline Negative $(n=14)$ & $6(42.9)$ & $8(57.1)$ & \\
\hline Blood group & & & 0.68 \\
\hline$O(n=16)$ & $5(31.2)$ & $11(68.8)$ & \\
\hline$A(n=26)$ & $10(38.5)$ & $16(61.5)$ & \\
\hline$B(n=14)$ & $5(35.7)$ & $9(64.3)$ & \\
\hline$A B(n=7)$ & $1(14.3)$ & $6(85.7)$ & \\
\hline Rh status & & & 0.42 \\
\hline Positive $(n=55)$ & $17(30.9)$ & $38(69.1)$ & \\
\hline Negative $(n=8)$ & $4(50.0)$ & $4(50.0)$ & \\
\hline
\end{tabular}

BMI: Body mass index; LNM: Lymph node metastasis.

was greater in the deceased patients compared with that of the censored group $(2.24 \pm 3.78$ vs $0.70 \pm 1.60$, respectively) $(p=0.03)$. The level of albumin was lower $(p=0.005)$ and the NLR was higher $(p=0.02)$ in the deceased group compared with the censored group. Clinicopathological 
Table 2. Clinicopathological and laboratory parameters of the LNM and non-LNM groups

\begin{tabular}{lccc}
\hline & $\begin{array}{c}\text { LNM }^{*} \\
(\mathbf{n}=\mathbf{2 1})\end{array}$ & $\begin{array}{c}\text { Non-LNM } \\
(\mathbf{n}=\mathbf{4 2})\end{array}$ & $\mathbf{p}^{* *}$ \\
\hline Age (years) & $57.71 \pm 9.58$ & $62.52 \pm 10.01$ & 0.09 \\
Follow-up time; & $28(11.5-56.5)$ & $29.5(13.5-55.5)$ & 0.91 \\
median (IQR) & & & \\
Total lymph nodes & $20.00 \pm 10.95$ & $16.02 \pm 9.53$ & 0.29 \\
Tumor size, cm & $2.10 \pm 1.24$ & $2.12 \pm 1.62$ & 0.75 \\
Hgb, g/L & $12.59 \pm 1.45$ & $13.10 \pm 2.07$ & 0.21 \\
Neutrophil, /mm & $5307.14 \pm 3613.04$ & $4975.05 \pm 1860.86$ & 0.69 \\
Lymphocyte, /mm & $2241.90 \pm 736.06$ & $2172.38 \pm 684.33$ & 0.62 \\
Monocyte, $/ \mathrm{mm}^{3}$ & $504.38 \pm 193.03$ & $552.24 \pm 203.32$ & 0.28 \\
Total protein, g/dL & $6.78 \pm 0.51(\mathrm{n}=11)$ & $7.08 \pm 0.43(\mathrm{n}=26)$ & 0.19 \\
Albumin, g/dL & $3.93 \pm 0.40(\mathrm{n}=11)$ & $4.15 \pm 0.38(\mathrm{n}=28)$ & 0.15 \\
CRP, mg/dL & $0.86 \pm 1.84(\mathrm{n}=8)$ & $1.61 \pm 3.04(\mathrm{n}=10)$ & 0.20 \\
CEA & $2.09 \pm 2.69(\mathrm{n}=12)$ & $1.77 \pm 1.73(\mathrm{n}=23)$ & 0.88 \\
NLR | & $2.67 \pm 2.22$ & $2.54 \pm 1.42$ & 0.61 \\
LMR & $4.91 \pm 2.02$ & $4.48 \pm 2.28$ & 0.25 \\
NMR & $10.84 \pm 4.94$ & $9.77 \pm 4.04$ & 0.60 \\
\hline
\end{tabular}

Mann-Whitney U test; CRP: C-reactive protein; CEA: Carcinoembryonic antigen; Hgb: Hemoglobin; IQR: Interquartile range; LMR: Lymphocyteto-monocyte ratio; LNM: Lymph node metastasis; NLR: Neutrophil-tolymphocyte ratio; NMR: Neutrophil-to-monocyte ratio.

Table 3. Clinicopathological and laboratory parameters of censored patients and those who died during follow-up

\begin{tabular}{|c|c|c|c|}
\hline & Censored $(n=46)$ & Deceased $(n=17)$ & $\mathbf{p}^{*}$ \\
\hline Age (years) & $60.17 \pm 9.73$ & $62.94 \pm 10.93$ & 0.22 \\
\hline $\begin{array}{l}\text { Follow-up time; } \\
\text { median (IQR) }\end{array}$ & $33.5(15.5-60)$ & $23(7-39)$ & 0.06 \\
\hline Total lymph nodes & $17.70 \pm 10.01$ & $16.41 \pm 10.64$ & 0.52 \\
\hline Metastatic lymph node & $0.70 \pm 1.60$ & $2.24 \pm 3.78$ & 0.03 \\
\hline Tumor size, cm & $2.14 \pm 1.57$ & $2.02 \pm 1.30$ & 0.99 \\
\hline $\mathrm{Hgb}, \mathrm{gr} / \mathrm{L}$ & $13.02 \pm 1.95$ & $12.70 \pm 1.75$ & 0.69 \\
\hline Neutrophil, /mm $\mathrm{mm}^{3}$ & $4642.87 \pm 1610.12$ & $6284.12 \pm 3988.29$ & 0.07 \\
\hline Lymphocyte, /mm³ & $2254.78 \pm 700.07$ & $2035.29 \pm 682.43$ & 0.22 \\
\hline Monocyte, /mm³ & $527.96 \pm 191.30$ & $558.82 \pm 225.50$ & 0.70 \\
\hline Total protein, g/dL & $7.07 \pm .41(n=28)$ & $6.74 \pm 0.57(n=9)$ & 0.15 \\
\hline Albumin, $\mathrm{g} / \mathrm{dL}^{* *}$ & $4.17 \pm 0.37(n=30)$ & $3.79 \pm 0.31(n=9)$ & 0.005 \\
\hline CRP g/dL ${ }^{* *} \neq$ & $1.14 \pm 2.63(n=14)$ & $1.75 \pm 2.46(n=4)$ & 0.22 \\
\hline CEA§ & $2.08 \pm 2.25(n=28)$ & $1.07 \pm 0.76(n=7)$ & 0.44 \\
\hline NLR $\|$ & $2.29 \pm 1.29$ & $3.36 \pm 2.41$ & 0.02 \\
\hline LMR १ & $4.81 \pm 2.30$ & $4.12 \pm 1.82$ & 0.39 \\
\hline NMRキキ & $9.44 \pm 3.09$ & $11.99 \pm 6.43$ & 0.56 \\
\hline
\end{tabular}

**Mann-Whitney $\mathrm{U}$ test; $\mathrm{p}<0.05$ was considered significant; CRP: C-reactive protein; CEA: Carcinoembryonic antigen; Hgb: Hemoglobin; IQR:

Interquartile range; LMR: Lymphocyte-to-monocyte ratio; NLR: Neutrophilto-lymphocyte ratio; NMR: Neutrophil-to-monocyte ratio. and laboratory parameters comparing the deceased and the censored groups are summarized in Table 3.

The mean survival time according to independent variables is presented in Table 4. There was no statistically significant difference, with the exception of NLR. The mean survival time was longer in the low-NLR group compared with the high-NLR group $(92.17 \pm 7.19$ months vs $41.46 \pm 5.51$ months; $p=0.003$ ), (Fig. 1). The mean survival for patients with LNM and without LNM was not statistically different $(62.36 \pm 10.56$ months and $71.99 \pm 5.57$ months, respectively; $p=0.09$ ), (Fig. 2). Patients who had LVI had a slightly shorter survival than patients who did not have LVI, but the result was not statistically significant ( $p=0.07$ ), (Fig. 3).

Table 4. Mean survival time according to demographic and clinicopathologic factors, log-rank test

\begin{tabular}{lcc}
\hline & Mean survival time \pm SE & p \\
\hline Gender & & 0.88 \\
Female & $79.37 \pm 10.70$ & \\
Male & $64.84 \pm 6.09$ & \\
Obesity & & 0.58 \\
No & $67.25 \pm 5.61$ & \\
Yes & $71.64 \pm 13.19$ & \\
Tumor location & & 0.73 \\
Antrum & $78.61 \pm 7.75$ & \\
Corpus & $67.78 \pm 12.38$ & \\
Cardia & $46.14 \pm 8.27$ & \\
Gastrectomy & & \\
Total & $57.70 \pm 10.72$ & \\
Distal & $79.74 \pm 7.61$ & \\
Lymph node metastasis & & \\
Yes & $62.36 \pm 10.56$ & \\
No & $71.99 \pm 5.57$ & \\
Stage & & 0.09 \\
1a & $72.36 \pm 6.76$ & \\
1b & $70.28 \pm 9.05$ & \\
Grade & & \\
High & & \\
Low & & \\
Lymphovascular invasion & & \\
Yes & & \\
No & & \\
Perineural invasion & & \\
Yes & & \\
No & & \\
Nigh & & \\
Low & & \\
\hline
\end{tabular}

NLR: Neutrophil-to-lymphocyte ratio. 


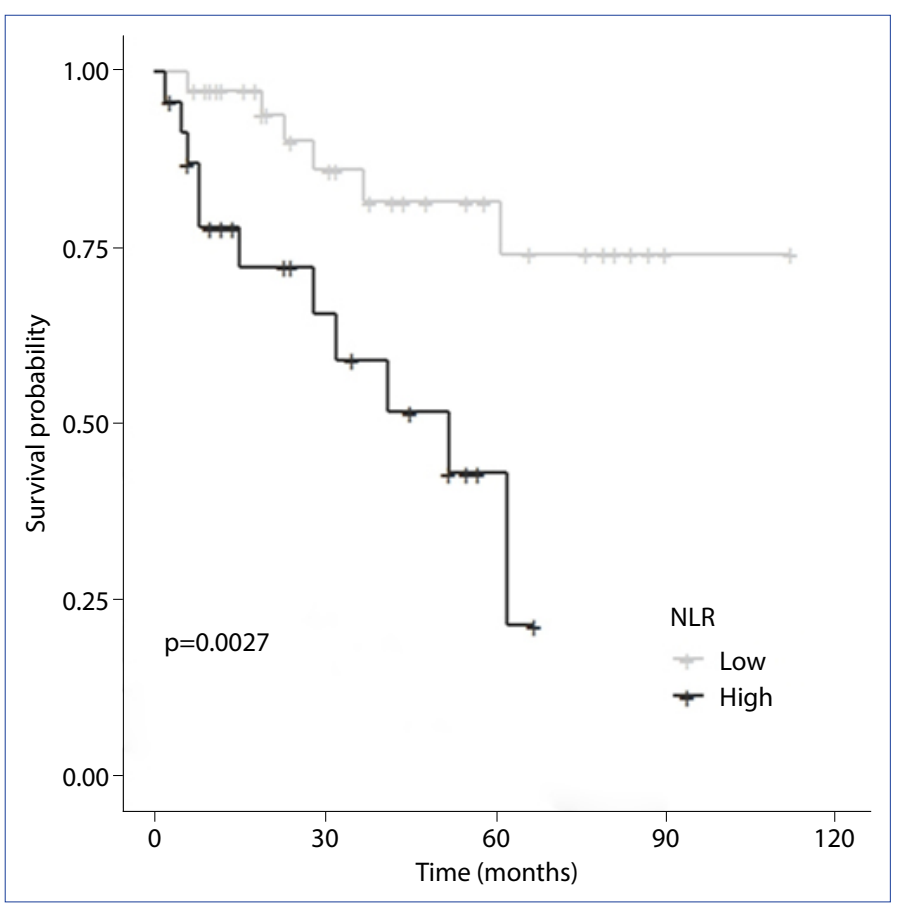

Figure 1. Kaplan-Meier survival curve according to the neutrophil-to-lymphocyte ratio (NLR).

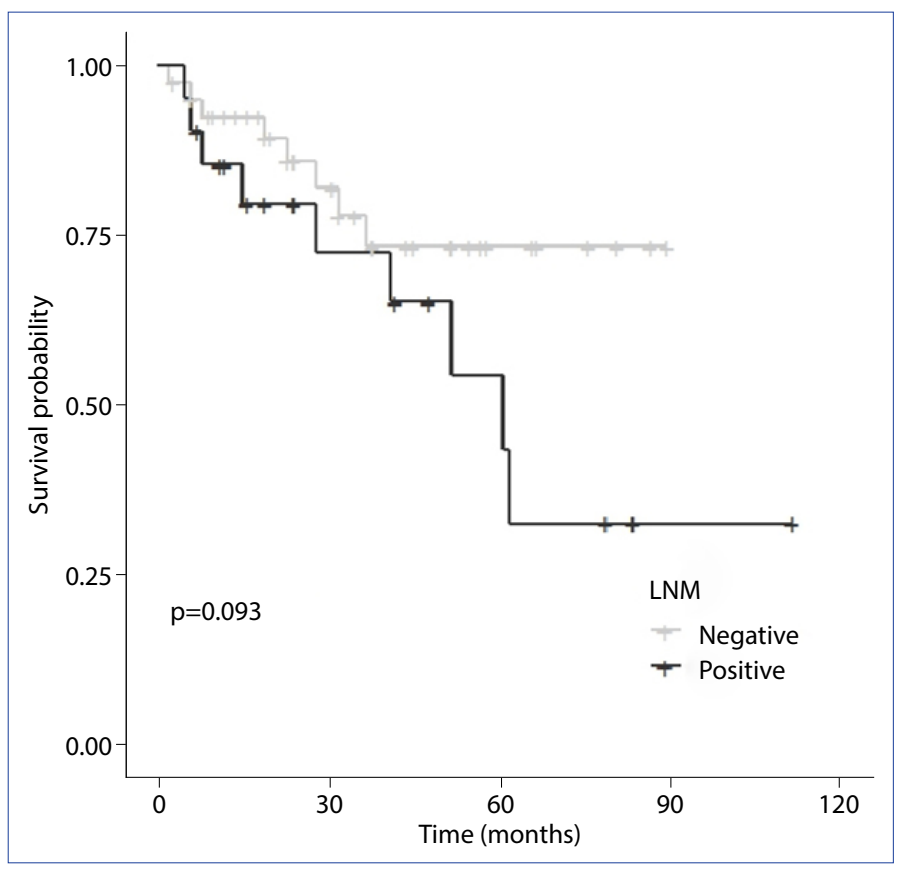

Figure 2. Kaplan-Meier survival curve according to lymph node metastasis (LNM).

\section{Determining Optimal Cut-off of NLR for Overall Survival}

There is no defined cut-off point for NLR. The optimal cutoff of NLR for overall survival was determined to be 2.332 when the Youden index was maximal (Fig. 4). The area

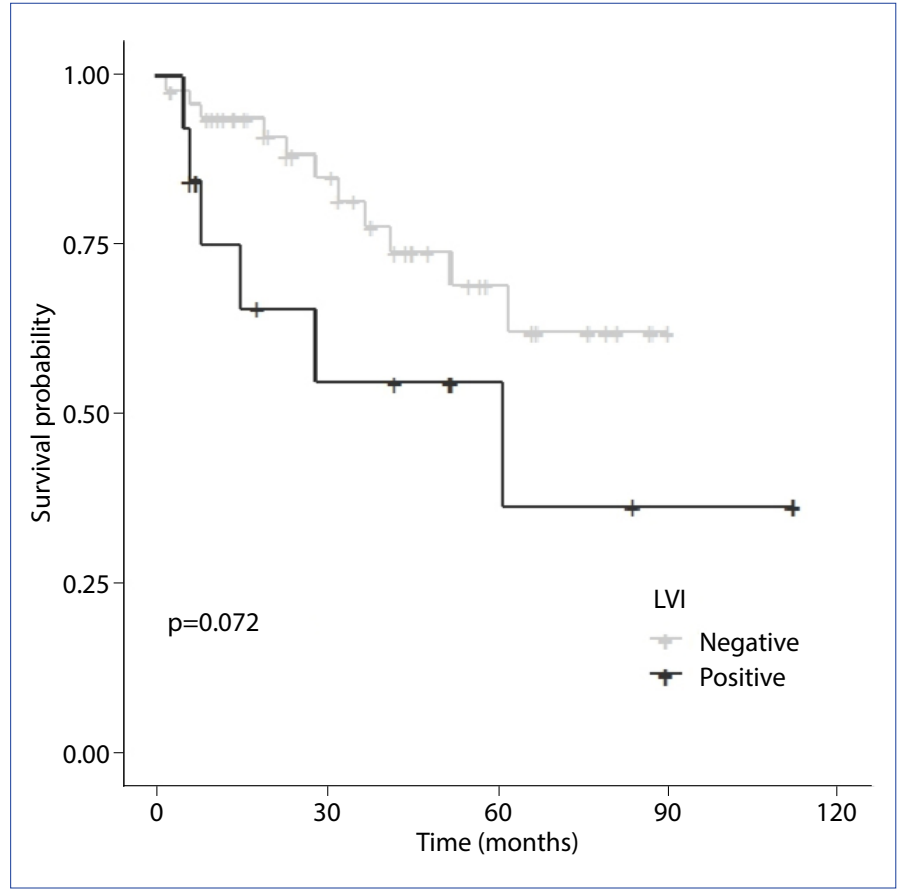

Figure 3. Kaplan-Meier survival curve according to lymphovascular invasion (LVI).

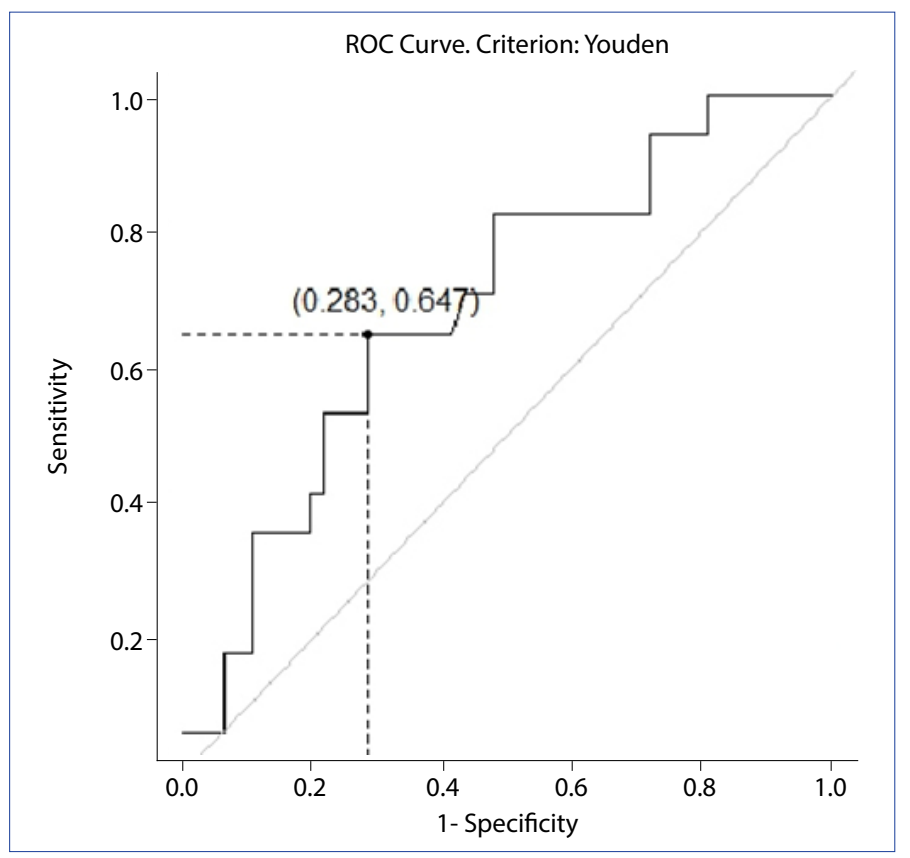

Figure 4. Receiver operating characteristic curve for the neutrophil-to-lymphocyte ratio (NLR) using the Youden index for optimal cut-off. Cut-off value: 2.332; Sensitivity: 64.7\%; Specificity: $71.7 \%$ (Area under the curve=0.69).

under the curve was 0.69 (95\% confidence interval [Cl]: $0.545-0.835)$. The NLR was high in 11 patients (64.7\%) and 13 patients $(28.3 \%)$ in the deceased and censored groups, respectively $(p=0.008)$. 


\section{Multivariate Analysis of LNM, LVI, and NLR}

Table 5 presents univariate and multivariate hazard ratios (HR) of 3 variables: LNM, LVI, and high NLR. High NLR was a strong predictive factor for mortality (HR: $4.15,95 \% \mathrm{Cl}$ : 1.51-11.36) in univariate analysis. When adjusted for age and gender, all 3 variables were significantly associated with death in Model 1 (HR for LNM: 3.42, 95\% Cl: 1.20-9.72; HR for LVI: 3.88, 95\% Cl: 1.31-11.44; HR for NLR: 4.03, 95\% Cl: 1.38-11.77). In Model 2, when the HR was adjusted for age and gender, and the other 2 variables, the HR for LNM was weakened and lost significance (HR: $2.51,95 \% \mathrm{Cl}$ : 0.847.44), but LVI and high NLR remained significant as strong predictors of survival.

\section{Discussion}

This study was an examination of factors affecting LNM and the survival of patients with early GC. Patient demographic characteristics and several other variables had no effect on LNM. LVI-positive and high-grade tumors were detected as factors that increased LNM. A review of the literature revealed that in 1577 early GC patients evaluated using the Surveillance, Epidemiology, and End Results Program of the US National Cancer Institute data, LNM was found to be $18.4 \%{ }^{[13]}$ In another study, the rate of LNM was $10.8 \%$ in 136 patients with signet ring cell-associated early GC. ${ }^{[14]}$ The incidence of LNM in our patients with early GC was $33.3 \%$, which is higher than results reported in the literature. This is likely due to the fact that ESD and endoscopic submucosal resection (ESR) are widely performed in the gastroenterology clinic of our hospital. In a study published by members of the gastroenterology clinic of our hospital, carcinoma was reported in 28 of 100 patients who underwent ESD. ${ }^{[15]}$ In that study, there was 1 case of morbidity. Patients who were not eligible for ESD were transferred for surgery.

Pokala et al. ${ }^{[13]}$ found that tumor size $>2 \mathrm{~cm}$, the invasion depth of the tumor (T1b), and poor differentiation were

Table 5. Cox proportional hazard regression models for death including age, gender, lymph node metastasis, lymphovascular invasion, and high NLR

\begin{tabular}{lccc}
\hline & Univariate & Model 1* & Model 2 † \\
\hline Lymph node metastasis & 2.21 & 3.42 & 2.51 \\
& $(0.85-5.74)$ & $(1.20-9.72)$ & $(0.84-7.44)$ \\
Lymphovascular invasion & 2.42 & 3.88 & 3.36 \\
& $(0.89-6.56)$ & $(1.31-11.44)$ & $(1.16-9.73)$ \\
High NLR & 4.15 & 4.03 & 3.58 \\
& $(1.51-11.36)$ & $(1.38-11.77)$ & $(1.13-11.35)$ \\
\hline
\end{tabular}

Hazard ratio (95\% Confidence interval); ${ }^{*}$ Adjusted for age and gender; †Adjusted for age, gender and the 2 other variables; NLR: Neutrophil-tolymphocyte ratio. statistically significant factors affecting LNM in both univariate and multivariate analyses. In that study, LVI was not determined to have any effect. Wang et al. ${ }^{[14]}$ reported that tumor size, depth of invasion, and LVI were predictive of LNM in patients with signet ring cell-associated early GC.

In our study, unlike other results, tumor size and invasion depth were not predictive factors for LNM. When the findings were examined in detail, LNM was seen in $26 \%$ of patients with a T1a tumor. Pokala et al. ${ }^{[13]}$ reported an incidence of $5 \%$. Our results related to LNM in patients with T2a tumors, however, were consistent with the literature. The LNM ratio was higher in patients with a tumor $<1 \mathrm{~cm}$ in diameter when compared with previous findings. In our analysis, LNM was detected in $61.5 \%$ of the patients with LVI, while LNM was detected in $26.0 \%$ of the non-LVI patients. In the literature, a reported rate of detection of LNM of $73 \%$ in the LVI-positive group was similar to our results. ${ }^{[16]}$

ESD is a frequently used method of treatment in early GC. Especially in Central Asia and the Far East, ESD is often performed instead of the classical radical resection. ${ }^{[17]}$ The ESD method is less invasive and takes less time than radical resection, permits a shorter postoperative hospital stay, and has a lower postoperative morbidity rate. There was no difference in survival between the 2 methods in a study comparing ESD, ESR, and gastrectomy. In order to obtain this result, ESD should be curative. ${ }^{[18]}$ However, an important risk of this procedure is that lymph node spread cannot be detected because lymph node resection is not performed. ${ }^{[15,19]}$ One of the most important reasons for the decision to perform surgery in patients with early GC is the possibility of LNM. Studies have also shown that in early GC, the risk of LNM is $2 \%$ to $5 \%{ }^{[20]}$ In a study evaluating early differentiated GC, the LNM finding was $5.5 \%{ }^{[21]}$

Endoscopic ultrasonography and abdominal CT are used to detect the presence of lymph nodes in the preoperative period. The sensitivity and specificity of these methods have been reported to be $75 \%$ and $89 \%$, respectively. ${ }^{[22]}$

The 2017 National Comprehensive Cancer Network guidelines recommend consideration of ESR or ESD for cases of early GC that meet the following criteria: tumor $\leq 2 \mathrm{~cm}$ in diameter, well or moderately differentiated, negative margins, limited to the superficial submucosa, and absence of LVI. ${ }^{[23]}$ Inflammatory parameters and LNM have also been investigated, but no effect was observed in the present study. Hu et al. ${ }^{[24]}$ analyzed 3012 GC patients. The subgroup analysis showed that the NLR value was related to LNM in early GC patients. NLR is one of the easily applicable parameters that show the body's immune response, systemic inflammation, and stress. ${ }^{[25]}$ The normal value varies according to race, place of residence, and age. Although a normal NLR of 
1.76 has been identified for the white race, this value is not considered to be a standard. ${ }^{[26]}$

In the 36-month mean follow-up period, 3 parameters (NLR, LNM, albumin) were found to be effective values when the parameters of the deceased and censored patients were compared in the present study. Kaplan Meier survival analysis indicated that the life expectancy of patients with an NLR value $>2.33$ was shorter. NLR values determined in survival studies of early GC patients vary in the literature. $\mathrm{Hu}$ et al. ${ }^{[24]}$ reported NLR cut-off rates of 1.87 and 2.61, while Zhu et al. ${ }^{[27]}$ found a cut-off value of 1.73 in their study. The overall survival was 42 months and 92 months for patients with high and low NLR values, respectively, in the present study. Receiver operating characteristic curve analysis of an NLR of 2.33 yielded an area under curve (AUC) value of 0.69 . An AUC value of 0.70 or more indicates that the studied parameter is validated. The value we obtained remained at the limit of validity. This suggests that an NLR of 2.33 should be validated for the prognosis related to other patient groups.

The 5 -year overall survival rate of early GC is over $90 \%$, reaching $95 \%$ in the group without $L N M .{ }^{[28]}$ It has been reported in recent years that inflammatory factors contribute to the spread and progression of malignancies and therefore, inflammatory indicators can be a predictive factor for both the spread and prognosis of cancers. NLR, NMR, LMR and the platelet-to-lymphocyte ratio (PLR) are the most commonly evaluated inflammatory parameters in cancer patients. These parameters have proved to be useful regarding the spread, postoperative morbidity, mortality, and survival in many cancer patients. ${ }^{[24,29,30]} \mathrm{A}$ meta-analysis also showed that a high NLR ratio was associated with poor prognosis. ${ }^{[31]}$ On the other hand, Zhu et al. ${ }^{[27]}$ examined the effect of both NLR and PLR on LNM and prognosis in early GC patients and they demonstrated that while the depth of tumor invasion was applicable to both LNM and prognosis, inflammatory parameters such as NLR, LMR had no effect.

Human epidermal growth factor receptor 2 (HER 2)-positivity has been described in the literature as a poor prognostic factor in GC. It was found that 14\% of HER 2 levels in gastric adenocarcinoma patients were positive and these patients had poor prognostic characteristics. ${ }^{[32,33]}$ In our series, HER 2 was examined in only 20 of the patients and $30 \%$ were found to be positive; LNM was not affected by HER 2-positivity.

Limitations of the present study include the retrospective design, small sample size, and reliance on the accuracy of written record analysis. The primary strength of the study is the long follow-up period. This study describes the results of a single tertiary institution. Multicenter studies including a larger number of patients are needed to confirm our results.

\section{Conclusion}

In conclusion, although ESR and ESD are common methods used in early GC, LNM can be seen in this patient group. Radical resection should be considered in patients who underwent endoscopic biopsy and have LVI and a high-grade tumor finding in the preoperative period. Patients who undergo radical surgery for early GC with a high preoperative NLR, LNM, and LVI should be considered to have shorter life expectancy. The NLR value is an independent predictor of survival in this patient group. A more aggressive surgery should be considered in patients with a NLR value $>2.33$. This value needs to be validated in other centers and studies.

\section{Acknowledgements}

Thank you to Prof. Dr. Belgin Unal (Dokuz Eylül University Faculty of Medicine, Department of Public Health, İzmir, Turkey) for assistance with the statistical analysis.

\section{Disclosures}

Ethics Committee Approval: Ethics committee approval for this study was received from the Ethics Committee of Katip Celebi University (date: 02.14.2018, decision number: 34 ).

Peer-review: Externally peer-reviewed.

Conflict of Interest: None declared.

Authorship Contributions: Concept - E.Ö.G.; Design - E.Ö.G., S.K.; Supervision - O.N.D., M.H.; Materials - E.Ö.G., E.K., H.K., O.N.D.; Data collection \&/or processing - N.E., A.N.E., S.K.; Analysis and/or interpretation - E.Ö.G., A.N.E., E.K.; Literature search - E.Ö.G., S.K., H.K.; Writing - E.Ö.G., S.K., O.N.D.; Critical review - E.Ö.G., M.H.

\section{References}

1. Kelley JR, Duggan JM. Gastric cancer epidemiology and risk factors. J Clin Epidemiol 2003;56:1-9. [CrossRef]

2. Goto O, Fujishiro M, Kodashima S, Ono S, Omata M. Outcomes of endoscopic submucosal dissection for early gastric cancer with special reference to validation for curability criteria. Endoscopy 2009;41:118-22. [CrossRef]

3. Zhong Q, Sun Q, Xu GF, Fan XQ, Xu YY, Liu F, et al. Differential analysis of lymph node metastasis in histological mixed-type early gastric carcinoma in the mucosa and submucosa. World J Gastroenterol 2018;24:87-95. [CrossRef]

4. Rice TW, Blackstone EH, Rusch VW. 7th edition of the AJCC Cancer Staging Manual: esophagus and esophagogastric junction. Ann Surg Oncol 2010;17:1721-4. [CrossRef]

5. Miyamae M, Komatsu S, Ichikawa D, Kosuga T, Kubota T, Okamoto $\mathrm{K}$, et al. Histological mixed-type as an independent risk factor for nodal metastasis in submucosal gastric cancer. Tumour Biol 2016;37:709-14. [CrossRef]

6. Yoon HJ, Kim YH, Kim JH, Kim H, Kim H, Park JJ, et al. Are new criteria for mixed histology necessary for endoscopic resection in early gastric cancer? Pathol Res Pract 2016;212:410-4. [CrossRef] 
7. Japanese Gastric Cancer Association. Japanese gastric cancer treatment guidelines 2014 (ver. 4). Gastric Cancer 2017;20:1-19.

8. Lee S, Choi KD, Hong SM, Park SH, Gong EJ, Na HK, et al. Pattern of extragastric recurrence and the role of abdominal computed tomography in surveillance after endoscopic resection of early gastric cancer: Korean experiences. Gastric Cancer 2017;20:843-52.

9. Tanabe S, Ishido K, Matsumoto T, Kosaka T, Oda I, Suzuki H, et al. Long-term outcomes of endoscopic submucosal dissection for early gastric cancer: a multicenter collaborative study. Gastric Cancer 2017;20:45-52. [CrossRef]

10. Kim DJ, Kim W. A case of single lymph node metastasis near the common hepatic artery following a curative endoscopic resection for gastric mucosal cancer. Gastric Cancer 2014;17:387-91.

11. Washington K. 7th edition of the AJCC cancer staging manual: stomach. Ann Surg Oncol 2010;17:3077-9. [CrossRef]

12. Youden WJ. Index for rating diagnostic tests. Cancer 1950;3:32-5.

13. Pokala SK, Zhang C, Chen Z, Gamboa AM, Cristofaro SL, Keilin SA, et al. Lymph node metastasis in early gastric adenocarcinoma in the United States of America. Endoscopy 2018;50:479-86. [CrossRef]

14. Wang Z, Zhang X, Hu J, Zeng W, Liang J, Zhou H, et al. Predictive factors for lymph node metastasis in early gastric cancer with signet ring cell histology and their impact on the surgical strategy: analysis of single institutional experience. J Surg Res 2014;191:130-3. [CrossRef]

15. Aslan F, Alper E, Cekıc C, Yurtlu DA, Ekıncı N, Arabul M, et al. Endoscopic submucosal dissection in gastric lesions: the 100 cases experience from a tertiary reference center in West. Scand J Gastroenterol 2015;50:368-75. [CrossRef]

16. Ahmad R, Setia N, Schmidt BH, Hong TS, Wo JY, Kwak EL, et al. Predictors of Lymph Node Metastasis in Western Early Gastric Cancer. J Gastrointest Surg 2016;20:531-8. [CrossRef]

17. Shin N, Jeon TY, Kim GH, Park DY. Unveiling lymph node metastasis in early gastric cancer. World J Gastroenterol 2014;20:5389-95.

18. Bausys R, Bausys A, Stanaitis J, Vysniauskaite I, Maneikis K, Bausys $B$, et al. Propensity score-matched comparison of short-term and long-term outcomes between endoscopic submucosal dissection and surgery for treatment of early gastric cancer in a Western setting. Surg Endosc 2019;33:3228-37. [CrossRef]

19. Wang S, Zhang Z, Liu M, Li S, Jiang C. Endoscopic Resection Compared with Gastrectomy to Treat Early Gastric Cancer: A Systematic Review and Meta-Analysis. PLoS One 2015;10:e0144774.

20. Choi KK, Bae JM, Kim SM, Sohn TS, Noh JH, Lee JH, et al. The risk of lymph node metastases in 3951 surgically resected mucosal gastric cancers: implications for endoscopic resection. Gastrointest Endosc 2016;83:896-901. [CrossRef]

21. Pyo JH, Byeon SJ, Lee H, Min YW, Min BH, Lee JH, et al. Measurement of tumor volume is not superior to diameter for prediction of lymph node metastasis in early gastric cancer with minute submucosal invasion. Oncotarget 2017;8:113758-65. [CrossRef]

22. Tsendsuren T, Jun SM, Mian XH. Usefulness of endoscopic ultrasonography in preoperative TNM staging of gastriccancer. World J Gastroenterol 2006;12:43-7. [CrossRef]

23. Ajani JA, D'Amico TA. National Comprehensive Cancer Network Gastric Cancer Guidelines. National Comprehensive Cancer Network; 2017: Version 5.2017. Available at: https://www.nccn.org/ professionals/physician_gls/pdf/gastric.pdf. Accessed Oct 26, 2017.

24. Hu D, Zhang H, Lin X, Chen G, Li C, Liang B, et al. Elevated preoperative neutrophil-to-lymphocyte ratio can predict poor survival in early stage gastric cancer patients receiving radical gastrectomy: The Fujian prospective investigation of cancer (FIESTA) study. J Cancer 2017;8:1214-22. [CrossRef]

25. Alexander NI. Reference Values of Neutrophil-Lymphocyte Ratio, Platelet-Lymphocyte-Ratio and Mean Platelet Volume in Healthy Adults in North Central Nigeria. J Blood Lymph 2016;6:143. [CrossRef]

26. Azab B, Camacho-Rivera M, Taioli E. Average values and racial differences of neutrophil lymphocyte ratio among a nationallyrepresentative sample of United States subjects. PLoS One 2014;9:e112361. [CrossRef]

27. Zhu GS, Tian SB, Wang H, Ma MG, Liu Y, Du HS, et al. Preoperative Neutrophil Lymphocyte Ratio and Platelet Lymphocyte Ratio CannotPredict Lymph Node Metastasis and Prognosis in Patients with Early Gastric Cancer: a Single Institution Investigation in China. Curr Med Sci 2018;38:78-84. [CrossRef]

28. Noh SH, Hyung WJ, Cheong JH. Minimally invasive treatment for gastric cancer: approaches and selection process. J Surg Oncol 2005;90:188-93. [CrossRef]

29. Kim DK, Oh SY, Kwon HC, Lee S, Kwon KA, Kim BG, et al. Clinical significances of preoperative serum interleukin- 6 and $C$-reactive protein level in operable gastric cancer. BMC Cancer 2009;9:155.

30. Kılınçalp S, Ekiz F, Başar O, Ayte MR, Coban S, Yılmaz B, et al. Mean platelet volume could be possible biomarker in early diagnosis and monitoring of gastric cancer. Platelets 2014;25:592-4. [CrossRef]

31. Zhang X, Zhang W, Feng LJ. Prognostic significance of neutrophil lymphocyte ratio in patients with gastric cancer: a meta-analysis. PLoS One 2014;9:e111906. [CrossRef]

32. Motoshima S, Yonemoto K, Kamei H, Morita M, Yamaguchi R. Prognostic implications of HER2 heterogeneity in gastric cancer. Oncotarget 2018;9:9262-72. [CrossRef]

33. Ikari N, Aoyama S, Seshimo A, Suehiro Y, Motohashi T, Mitani $S$, et al. Somatic mutations and increased lymphangiogenesis observed in a rare case of intramucosal gastric carcinoma with lymph node metastasis. Oncotarget 2018;9:10808-17. [CrossRef] 